\title{
Numerical Analysis on Particle-Laden Rotating Turbulent Flow
}

\author{
（固気二相回転乱流の数值解析）
}

\author{
潘 応康 \\ Yingkang Pan
}

\section{Background}

As we know, the particle-laden turbulent flow in the rotating system is very important in many industrial fields. In such a rotating system, particle's trajectories are much affected by the Coriolis and centrifugal forces, so that they considerably deviate from the streamlines of the carrier fluid. This results in a concentration gradient across the rotating system and causes a change in the properties of the fluid flow and particle distributions. The net results are changes in the turbulence structure, its intensity and timeaveraged velocity distribution. If the particles are of erosive nature, the impact of the particles on surfaces can cause severe erosion damage. Engineering applications are even more numerous, to mention a few: gas turbines operating with working fluids containing solid pariticles, induced fans working in the air containing dusts. There exist some industry experiences, but little is known about the mechanisms of particle concentration and their interaction and the turbulence modification due to them in the rotating system. Even given today's sophisticated laser measurements, it is still difficult to observe the behavior of particles and their inter-particle collisions, and turbulence modulation in detail. With modern supercomputers, it is possible to predict the motions of particles and fluid instantaneously. The selected topic is valuable to do but it is a challenge. After investigating, I decided to accept this challenge by applying the techniques of Large-Eddy Simulation (LES) and Direct Numerical Simulation (DNS) for the carrier fluid and the deterministic method for the particles in simplified rotating systems.

\section{Introdution}

Turbulence modification by particles will occur when the particle volume fraction reaches $O\left(10^{-5}\right)$ for most gas -

\section{1 年 6 月 8 日受付}

(株) 荏原総合研究所 技術研究セン夕- 機械系技術研究室

（干251-8502 藤沢市本藤沢 4丁目 2 番 1 号) TEL 0466-83-7608

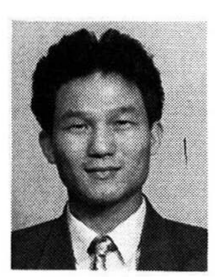

$$
\text { <著者紹介> }
$$

昭和61年 7 月中国上海機械学院動力工程采卒 業. 平成元年 6 月同大学院動力工学科数値流 体力学専攻修士課程修了, 平成 13 年 3 月大阪 大学大学院工学研究科 機械物理工学専攻博 士後期課程修了, 同年 4 月より（株）荏原総 合研究所 技術研究センター 機械系技術研 究室研究員, 現在に至る。博士 (工学) 専門：混相流, 乱流, ターボ機械 solid or gas-liquid flows, in which turbulence modification by the particles is not negligibly small. There are many experimental investigations on turbulence modification by particles in jet, pipe and channel flow configurations. In general, large particles tend to increase the intensity of the fluid-phase turbulence, whereas small particles decrease it. It is extremely difficult to set the experimental apparatus to observe the behavior of particles and their inter-particle collisions in detail in rotating systems. Other scientists had conducted many experiments and numerical investigations concerning the effects of solid particles on the performance of turbomachines. They only employed an inviscid model for fluid and traced few particles using Lagrangian method. Therefore, the turbulence modulation by solid particles could not be done in their modeling. Until now, the motion of particles in turbomachines is still too difficult to be observed both experimentally and numerically in detail. Therefore, the simplified rotating channel and rotating cube are regarded as the standard settings for fundamental studies on effects of Coriolis and centrifugal forces in turbomachines.

Based on above situations, I decided to apply the LES and DNS techniques for solving the Navier-Stokes equations along with the continuity and the deterministic method of particles with a hard-sphere model for inter-particle collisions to predict the flow field in rotating channels, in a rotating cube and the trajectories of particles.

\section{Main Results}

This dissertation has been devoted to the fundamental understanding of particle performance and turbulence modulation by particles in the rotating systems. The direct numerical simulation and the large-eddy simulation have been developed in particle-laden rotating turbulent flows. The effect of rotation on both the fluid and particles has been discussed, and the effect of inter-particle collisions has been studied in detail. The results of this study are summarized as follows:

\section{1 LES of pariticle- laden rotating channel flows}

Large-eddy simulations of the particle-laden rotating channel flows have been developed and compared with the single-phase flows at the Reynolds number $R e_{\tau}=u_{\tau} H / \nu$ $=250$ and the Rotation number $R o_{\tau}=\Omega H / u_{\tau}=0.0,0.1$, $0.25,0.5,1.0$, and 1.5 , respectively. Smagorinsky SGS model has been employed in the large-eddy simulations.

Many particles accumulate in the region near the pressure surface due to system rotation even at the low Rotation number in fully developed rotating turbulent channel flows. 
The turbulence properties and structures are modified by Coriolis forces and particles. Those phenomena are very obvious near the two walls.

The inter-particle collisions play an important role even at a low averaged particle volume fraction $O\left(10^{-5}\right)$ and change the particle density distributions. The effeet of the finite-sized particles is to attenuate the contributions of Coriolis forces on the turbulence and the total turbulent kinetic energies of the carrier fluid in a rotating channel.

\section{2 DNS of particle- laden rotating channel flows}

DNS of the turbulent rotating channel flows at the Reynolds number $R e_{\tau}=u_{\tau} H / \nu=194$ and the Rotation number $R o_{\tau}=\Omega H / u_{\tau}=0.075$ laden with small particles has been performed. Three particle sets of different diameters and densities with the same number were followed with the two way coupling through point force modeling. Particle gravity parallel to the spanwise direction and particle volume fractions from $O\left(10^{-6}\right)$ to $O\left(10^{-5}\right)$ were considered. It is found that the effects of $50 \mu \mathrm{m}$ glass and $70 \mu \mathrm{m}$ copper particles and their inter-particle collisions are significant to change the turbulence properties, particularly in the near wall region. The DNS results also show that the inter-particle collisions make the lighter particle distributions more uniform and then suppress the fluid turbulence, and make the heavier particle distributions more uneven and then enhance the fluid turbulence.

From the results of the mean one-dimensional energy spectra, it is found that for the larger and heavier particles in a rotating channel, the effect of the inter-particle collisions is to increase the turbulence kinetic energy of the fluid. The increasing level of turbulence kinetic energy at low wavenumbers is significant in the core region of the channel, while the increasing level of turbulence kinetic energy at high wavenumbers is relatively significant in the near-wall regions.

For the larger and heavier particles (e.g. $70 \mu \mathrm{m}$ copper particles), they contribute to the Reynolds stress budgets directly near the pressure surface due to particle concentration in this region. Moreover, they have a positive contribution to $\overline{u^{2}}$ or $\overline{v^{2}}$ in the vicinity of the pressure surface and negative one slightly far from it, and a negative contribution to $u v$ in the vicinity of the pressure surface. The dissipation and viscous diffusion are modified consequently by the particles. For the cases not considering the inter-particle collisions, the magnitudes of the peaks of the Reynolds stress close to the pressure surface are suppressed and their positions are moved away from the wall, and the magnitudes are very small near the suction surface compared with the corresponding case considering the inter-particle collisions. Production term due to system rotation plays an important role in the $\overline{u v}$ equation. A strong streaky structures added "hooks" with a certain skew angle to the streamwise direction near the pressure surface are found to the case with $50 \mu \mathrm{m}$ glass particles (see Fig. 1). The well-known low/high speed streaks close to the boundary are destroyed by the $70 \mu \mathrm{m}$ copper particles due to system rotation (see Fig. 2).

3. 3 Dynamics of particle concentration and turbulence modulation of particle-laden rotating turbulence

This part has shown the dynamics of particle concentration and turbulence modulation in rotating turbulence by the DNS of a particle-laden rotating cube. We have

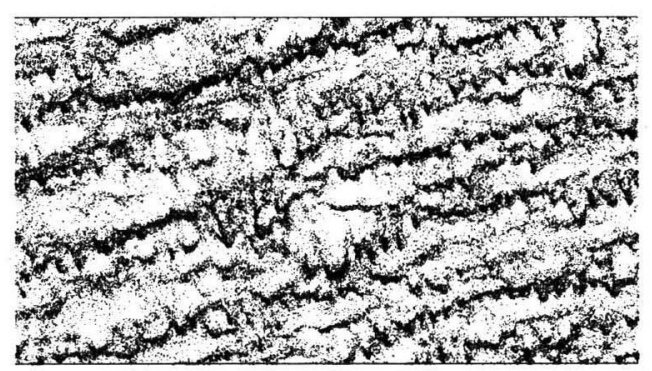

Fig. 1 Instantaneous glass particle distribution structures near the pressure surface

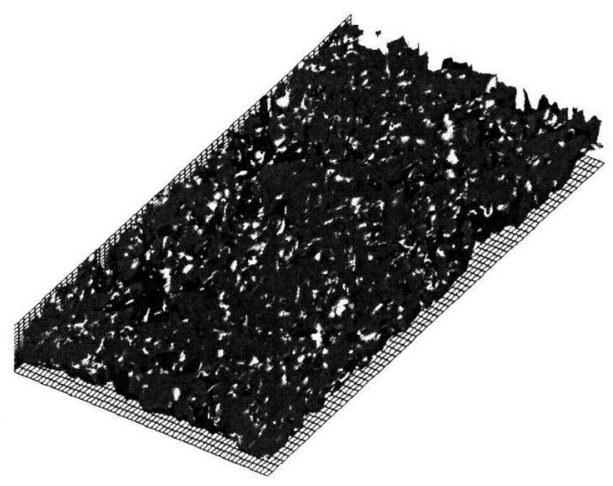

Fig. 2 Streamwise isovorticity surfaces near the pressure surface with Copper particles (grey: positive ; black: negative)

obtained the following conclusions :

The particle clusters parallel to the rotating axis are found due to strong rotation. The simulated particles follow the fluid well in decaying turbulence without system rotation.

It is found that the fluid turbulence modulation in a rotating cube by particles can be decided by observing the ratio of the rotation time scale $(1 /(2 \Omega))$ to the particle momentum time scale $\tau_{\mathrm{p}}$. Particles enhance the fluid turbulence for the strong rotation cases after a period of time. From simulated results it is obtained that the interparticle collision rate increases by increasing the rotating angular velocity $\Omega$. When the rotating angular velocity becomes higher, the inter-particle collision rate will vibrate as time goes on.

From the DNS results, it is also found that rotation and particles have an anisotropic effect on the fluid turbulence. The fluid-particle cross terms of one-point velocity correlations are not negligibly small when the rotation time scale $(1 /(2 \Omega))$ is smaller than the momentum particle response time $\tau_{\mathrm{p}}$.

\section{Acknowledgements}

The author is deeply indebted to Professor Yutaka Tsuji, Associate Professor Toshitsugu Tanaka, Associate Professor Muneyuki Yoshioka, and Assistant Professor Toshihiro Kawaguchi of Osaka University.

(Ph.D. awarded in March 2001, Osaka University) 